Aziz Epik

\title{
Die Strafzumessung bei Taten nach dem Völkerstrafgesetzbuch
}

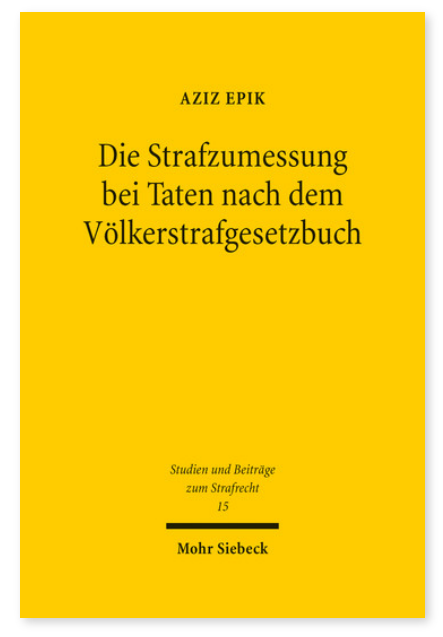

2017. XXIV, 554 Seiten. StudStR 15

ISBN 978-3-16-155206-9

DOI 10.1628/978-3-16-155206-9

eBook PDF 144,00 €

ISBN 978-3-16-155121-5

Leinen $144,00 €$
Das Völkerstrafgesetzbuch bildet die Rechtsgrundlage für die Verfolgung von Völkerrechtsverbrechen durch die deutsche Justiz. Erfasst sind Völkermord, Verbrechen gegen die Menschlichkeit, Kriegsverbrechen und seit kurzem auch das Verbrechen der Aggression. Für die Strafzumessung trifft das Gesetz allerdings keine besonderen Regelungen, sondern verweist auf das allgemeine deutsche Strafzumessungsrecht. Aziz Epik untersucht, ob diese Lösung sachgerecht ist und es ermöglicht, die Besonderheiten dieser Taten bei der Strafzumessung zu berücksichtigen. Zu diesem Zweck unternimmt er eine umfassende vergleichende Analyse des deutschen und des völkerrechtlichen Strafzumessungsrechts und widmet sich insbesondere den maßgeblichen Strafzwecken und Strafrahmen des Völkerstrafgesetzbuches, der Methode der Strafzumessung sowie den dabei zu berücksichtigenden Strafzumessungskriterien.

Aziz Epik Geboren 1989; Studium der Rechtswissenschaften an der Humboldt-Universität zu Berlin; 2013 Erste Juristische Staatsprüfung; 2016 Promotion; seit 2013 Wissenschaftlicher Mitarbeiter am Lehrstuhl für deutsches und internationales Strafrecht, Strafprozessrecht und Juristische Zeitgeschichte an der Humboldt-Universität zu Berlin.

Jetzt bestellen:

https://mohrsiebeck.com/buch/die-strafzumessung-bei-taten-nach-dem-voelkerstrafgesetzbuch-9783161552069?no_cache=1 order@mohrsiebeck.com

Telefon: +49 (0)7071-923-17

Telefax: +49 (0)7071-51104 